\title{
COMPARATIVO DO DESEMPENHO DE CULTURAS ADVINDAS DE FONTES DIFERENTES NA BIODEGRADAÇÃO ANAERÓBIA DE BIODIESEL
}

\author{
L. P. N. MARÇON, M. S. KASHIWABARA, E. J. RIBEIRO, P. A. VIEIRA \\ Universidade Federal de Uberlândia, Faculdade de Engenharia Química \\ E-mail para contato: lorenapnmarcon@gmail.com
}

\begin{abstract}
RESUMO A intensiva busca por fontes alternativas de energia e processos sustentáveis visando a redução da poluição ambiental e o aquecimento global do planeta tem estimulado o mercado mundial de combustíveis limpos como o biodiesel, que representa uma alternativa renovável e ambientalmente segura aos combustíveis fósseis. Mas, decorrente deste aumento de produção as possibilidades de ocorrência de acidentes são grandes e consequentemente as contaminações do ambiente são crescentes. Os processos biológicos, envolvendo uma grande gama de microrganismos de fontes diferentes adaptadas podem se tornam uma alternativa interessante no tratamento de efluentes contaminados por biodiesel. Portanto, este trabalho avalia a potencialidade de microrganismos de fontes diferentes biodegradar o biodiesel como fonte de carbono. Foram testadas duas culturas, uma mista (C1) facultativa advinda de local contaminado por derivados de petróleo (óleo diesel e gasolina), e outra cultura (C2) advinda de lodo de sistema de tratamento anaeróbio de efluentes da indústria de produção de cigarros, ambas previamente adaptadas ao biodiesel em meio líquido. Cada uma das culturas apresentaram meios de cultivo (M1 para cultura mista e M2 para o lodo), previamente preparados e esterilizados e condições de processos diferenciados, em função dos microrganismos empregados. As variáveis de resposta foram $\mathrm{pH}$ e remoção de DQO. Dentro desta concepção, a cultura que apresentou maior capacidade em biodegradar o biodiesel foi a cultura C2 no tempo de 7 dias de processo. Estes resultados mostram que a fonte do tipo de cultura interfere na capacidade de remoção do contaminante e isto está associado a seu potencial metabólico.
\end{abstract}

\section{INTRODUÇÃO}

Com o crescimento da produção de biodiesel aumenta-se significativamente a probabilidade de derramamentos acidentais durante o processo, transporte e armazenagem, potencializando o risco de contaminação do ambiente (solo e água). Devido a isso, técnicas de tratamento de solo e água contaminado por hidrocarbonetos derivados do biodiesel têm sido alvo de inúmeros estudos e constituem um grande desafio para a comunidade científica que busca obter métodos eficazes, economicamente viáveis e compatíveis com os aspectos socioambientais atuais. Devido à complexidade e diversidade das contaminações, não há uma regra que determine o melhor tratamento a ser utilizado. Cada caso deve ser analisado individualmente, avaliando suas particularidades. Em geral, o sucesso da técnica empregada 
depende das condições físicas, químicas e biológicas do local contaminado, do tempo de exposição, tipo e concentração do contaminante e do tempo requerido para a remoção do composto alvo (ANDRADE et al., 2010).

A utilização de culturas puras (bactérias, leveduras ou fungos filamentosos) e mistas nos processos de descontaminação é uma alternativa tecnológica bastante promissora, por muitas vezes ser capaz de proporcionar limpeza ou diminuição da carga poluidora que possa estar presente em solo ou em meio líquido (BIELICKA et al., 2002; PIEDADE et al., 2000; LAKHA et al., 2005; TOWNSEND et al., 2004; GOGOI et al., 2003).

\section{OBJETIVOS}

O objetivo geral deste projeto é comparar o desempenho de duas culturas de fontes diferentes no processo de biodegradação anaeróbia de biodiesel.

\section{MATERIAIS E MÉTODOS}

\subsection{Biodiesel}

O biodiesel utilizado para o desenvolvimento desta pesquisa foi gentilmente fornecido pela Caramuru Alimentos S/A - São Simão - GO.

\subsection{Microrganismo}

Foram empregados dois inóculos durante a execução deste trabalho. Inicialmente, foi utilizada a cultura mista denominada C1 empregada nos trabalhos de Vieira et al. (2007 e 2010). Essa cultura foi isolada do solo de uma lagoa que recebe o efluente gerado na lavagem do pátio e dos caminhões de uma distribuidora de combustíveis situada na cidade de Uberlândia-MG. O lodo denominado de C2 foi gentilmente cedido pela Souza Cruz - Fábrica Uberlândia- MG da unidade de tratamento anaeróbio de efluentes.

\subsection{Adaptação}

As culturas $\mathrm{C} 1$ e $\mathrm{C} 2$ foram previamente adaptadas ao biodiesel em meio líquido. A adaptação para a cultura mista ao biodiesel em meio líquido foi realizado centrifugando 40 $\mathrm{mL}$ da cultura mista, denominada C1 (empregada nos trabalhos de VIEIRA et al., 2010) obtida do estoque de microrganismos do Núcleo de Biotecnologia da Faculdade de Engenharia Química/UFU. Em erlenmeyers com capacidade de $250 \mathrm{~mL}$, contendo $100 \mathrm{~mL}$ de meio de cultura, denominado de $\mathrm{M} 1$, previamente esterilizados a $121^{\circ} \mathrm{C}$ e $1 \mathrm{~atm}$ e quimicamente definido (g/L): $\mathrm{K}_{2} \mathrm{HPO}_{4} 0,401 ; \mathrm{KH}_{2} \mathrm{PO}_{4} 1,124 ; \mathrm{CaCl}_{2} 0,020 ; \mathrm{MnSO}_{4} \cdot \mathrm{H}_{2} \mathrm{O}$ 0,$030 ; \mathrm{MgSO}_{4} .7 \mathrm{H}_{2} \mathrm{O} 0,100 ; \mathrm{NH}_{4} \mathrm{NO}_{3} 3,386$; levedura cervejeira autolizada 4,000, sendo adicionado o inóculo centrifugado. A esta suspensão foi adicionada inicialmente $0,25 \% \mathrm{v} / \mathrm{v}$ de biodiesel como fonte de carbono e energia para os microrganismos. Os erlenmeyers foram tampados com rolha de algodão e gaze, uma vez que a cultura era facultativa, sob agitação em mesa oscilatória termostatizada New Brunswick a $150 \mathrm{rpm}$ e temperatura ambiente.

Para adaptação do lodo (C2) ao biodiesel em meio líquido, foi decantado $500 \mathrm{~mL}$ do lodo em um béquer com capacidade de $1 \mathrm{~L}$, do qual foi retirado $10 \mathrm{~mL}$ de inóculo e adicionado em erlenmeyers com capacidade de $500 \mathrm{~mL}$, contendo $200 \mathrm{~mL}$ de meio de cultura 
previamente esterilizados a $121^{\circ} \mathrm{C}$ e 1 atm e quimicamente definido, meio $\mathrm{M} 2$ (g/L): $\mathrm{K}_{2} \mathrm{HPO}_{4}$ 0,$005 ; \mathrm{KH}_{2} \mathrm{PO}_{4} 0,003 ; \mathrm{NH}_{4} \mathrm{Cl} 0,164 ; \mathrm{CaCl}_{2} .2 \mathrm{H}_{2} \mathrm{O} 0,100 ; \mathrm{MgSO}_{4} .7 \mathrm{H}_{2} \mathrm{O} 0,200 ; \mathrm{FeCl}_{3} .6 \mathrm{H}_{2} \mathrm{O}$ 0,$002 ; \mathrm{MnCl}_{2} \cdot 4 \mathrm{H}_{2} \mathrm{O}$ 0,0005; levedura cervejeira autolizada 0,500. A esta suspensão foi adicionado o biodiesel como fonte de carbono e energia. Os erlenmeyers foram purgados por 5 min com gás nitrogênio, visando eliminar o oxigênio presente e garantir a condição anaeróbia, e imediatamente foram tampados com rolha de cortiça, as quais foram adaptadas por uma mangueira. As pontas dessas mangueiras foram colocadas na superfície da água presente em frascos de penicilina de $100 \mathrm{~mL}$ para verificação dos gases formados. Os erlenmeyers foram postos sob agitação em mesa oscilatória termostatizada New Brunswick a $150 \mathrm{rpm}$ e temperatura ambiente. O meio de cultura foi substituído a cada 2 dias de processo devido a possibilidade de produção de substâncias tóxicas pelos microrganismos.

\subsection{Experimentos em Anaerobiose}

Os experimentos com a cultura mista $(\mathrm{C} 1)$ foram realizados em frascos tipo penicilina de $100 \mathrm{~mL}$ de capacidade, vedados com tampas de borracha e lacres metálicos a fim de garantir a condição de anaerobiose. Aos frascos tipo penicilina foram adicionados $80 \mathrm{~mL}$ de meio de cultivo e os seguintes compostos (g/L): $\mathrm{K}_{2} \mathrm{HPO}_{4} 0,0022 ; \mathrm{KH}_{2} \mathrm{PO}_{4} 0,0078 ; \mathrm{CaCl}_{2}$ 0,$020 ; \mathrm{MnSO}_{4} . \mathrm{H} 2 \mathrm{O} 0,030 ; \mathrm{MgSO}_{4} .7 \mathrm{H}_{2} \mathrm{O} 0,100 ; \mathrm{NH}_{4} \mathrm{NO}_{3} 0,143$ e $\mathrm{FeSO}_{4} .7 \mathrm{H}_{2} \mathrm{O}$ 0,5; levedura cervejeira autolizada 4,000. O tamponamento do meio foi realizado com $\mathrm{NaHCO}_{3}$ 0,6325 g/L. Após esta adição os frascos foram purgados por 2 min com gás inerte (Argônio) visando eliminar o oxigênio presente e tampados com rolhas de borracha e lacrados com lacres em alumínio. Posteriormente, foram levados a esterilização a $121^{\circ} \mathrm{C}$ e $1 \mathrm{~atm}$, por $20 \mathrm{~min}$. Após resfriamento dos frascos estes foram inoculados, empregando seringas, com $8 \mathrm{~mL}$ de inóculo previamente adaptado. Com auxílio de seringas descartáveis foi adicionada a concentração de $0,5 \% \mathrm{p} / \mathrm{v}$ de biodiesel. Os frascos foram então dispostos em uma mesa agitadora a $110 \mathrm{rpm}$, na temperatura ambiente de $28 \pm 2^{\circ} \mathrm{C}$. A estes frascos visando verificar a produção de gás e controle de pressão dentro do sistema foi fixada à tampa do frasco seringas descartáveis, como mostrado na Figura 1.

Figura 1 - Esquema do sistema anaeróbio empregado para o desenvolvimento da cultura C1.

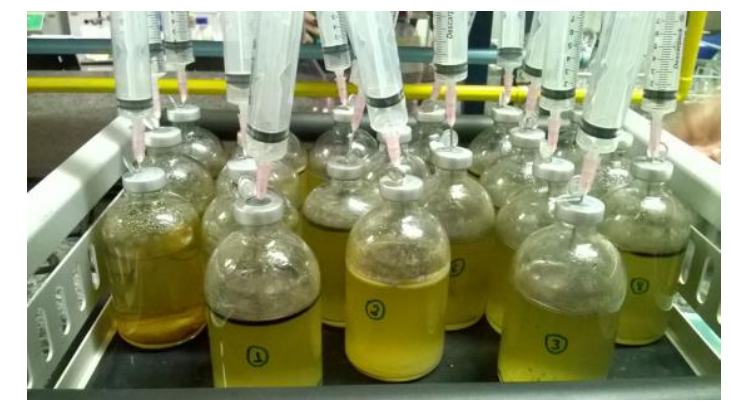

Os experimentos com o lodo $(\mathrm{C} 2)$ foram realizados em erlenmeyers com capacidade de $500 \mathrm{~mL}$, vedados com rolhas de cortiça adaptadas com mangueiras, para garantir a condição de anaerobiose. Aos erlenmeyers foi adicionado meio de cultura M2, descrito no item 3.3 e previamente esterilizado a $121^{\circ} \mathrm{C} \mathrm{e} 1 \mathrm{~atm}$, por $20 \mathrm{~min}$. $\mathrm{O}$ tamponamento do meio foi feito com

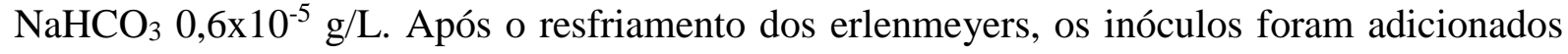
aos mesmos e foi feita a purga de cada erlenmeyer por 5 min com gás nitrogênio visando eliminar o oxigênio presente, e, ao final da etapa de purga foi adicionado a cada erlenmeyer a 
concentração de $0,5 \%$ p/v de biodiesel. Os erlenmeyeres foram então dispostos em uma mesa agitadora a $150 \mathrm{rpm}$, na temperatura ambiente de $28 \pm 2^{\circ} \mathrm{C}$. A Figura 2 mostra o esquema empregado para a cultura $\mathrm{C} 2$.

Figura 2 - Esquema do sistema anaeróbio empregado para o desenvolvimento da cultura C2.

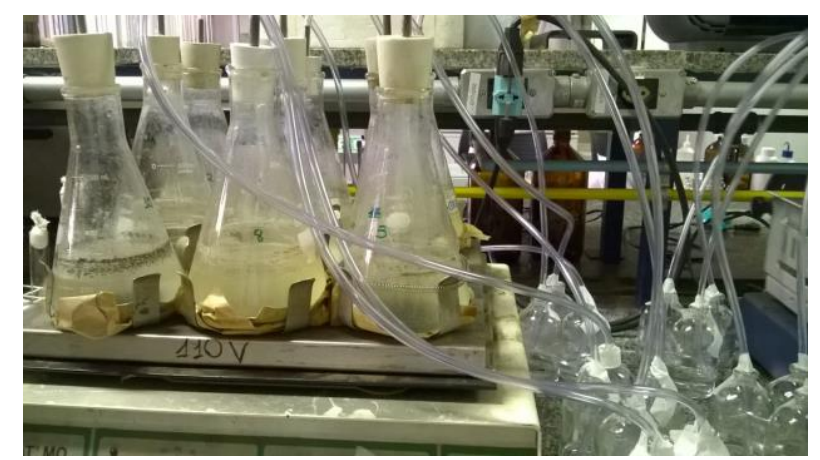

Após o tempo de processo para ambos os inóculos, foram avaliadas as repostas de $\mathrm{pH}$ e demanda química de oxigênio (DQO).

\subsection{Análises Quantitativas}

Análise de $\mathrm{pH}$ : A determinação do $\mathrm{pH}$ foi de acordo com o procedimento descrito em APHA (1998). A leitura do pH das amostras foi realizada pelo método potenciométrico, utilizando phmetro, introduzindo o eletrodo diretamente nas amostras líquidas.

Análise de demanda química de oxigênio (DQO): Para a determinação da DQO por espectrofotometria foram realizados os seguintes passos empregando a preparação de solução de digestão para alta concentração (absorbância de $600 \mathrm{~nm}$ ): Adicionou-se em $500 \mathrm{~mL}$ de água destilada $10,126 \mathrm{~g} \mathrm{~K}_{2} \mathrm{Cr}_{2} \mathrm{O}_{7}$, grau padrão primário, previamente seco em $150^{\circ} \mathrm{C}$ por $2 \mathrm{~h}$, $167 \mathrm{~mL}$ de $\mathrm{H}_{2} \mathrm{SO}_{4}$ concentrado e $33,3 \mathrm{~g} \mathrm{HgSO}_{4}$. Dissolveu-se a temperatura ambiente e diluiu-se a $1000 \mathrm{~mL}$. Usaram-se as seguintes relações de reagentes e amostra: 2,5 mL de amostra; 1,5 mL da solução de dicromato e 3,5 mL da solução de ácido sulfúrico para os tubos de ensaio adequados para o bloco digestor. A digestão ocorreu por $2 \mathrm{~h}$ a $150^{\circ} \mathrm{C}$. Para o preparo da curva de calibração empregou-se 5 padrões de biftalato de potássio com DQO equivalentes para cobrir cada limite de concentração. Para o branco, usou-se os mesmos volumes de reagentes, tubos e procedimento de digestão das amostras.

\section{RESULTADOS}

A Figura 3 e 4 mostram os resultados obtidos de $\mathrm{pH}$ e remoção de DQO para as culturas avaliadas, $\mathrm{C} 1$ e $\mathrm{C} 2$, nos tempos $0,2,7$ e 12 dias. 


\section{Congresso Brasileiro de Engenharia Química em Iniciação Científica UFSCar - São Carlos - SP 16 a 19 de Julho de 2017}

Figura 3 - Comportamento do pH em função do tempo para ambos inóculos utilizados.

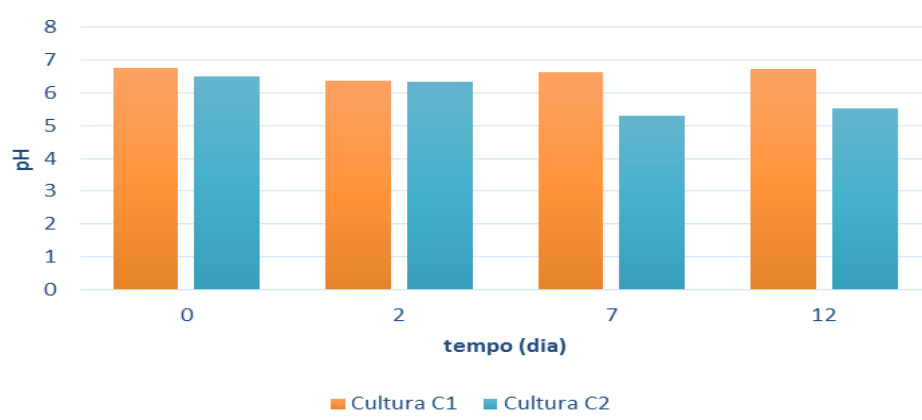

Por meio da Figura 3, pode-se verificar o comportamento do $\mathrm{pH}$ ao longo do tempo de processo. Pode-se verificar, que a cultura $\mathrm{C} 2$ apresentou $\mathrm{pH}$ mais ácido, em torno de 5,5 em 7 e 12 dias de processo, sugerindo que houve produção de maior quantidade de ácidos decorrentes do metabolismo deste microrganismo. A cultura $\mathrm{C} 1$ (mista) apresentou $\mathrm{pH}$ próximo da neutralidade durante todo o período.

Figura 4 - Resultados da remoção de DQO em função do tempo para ambos inóculos utilizados.

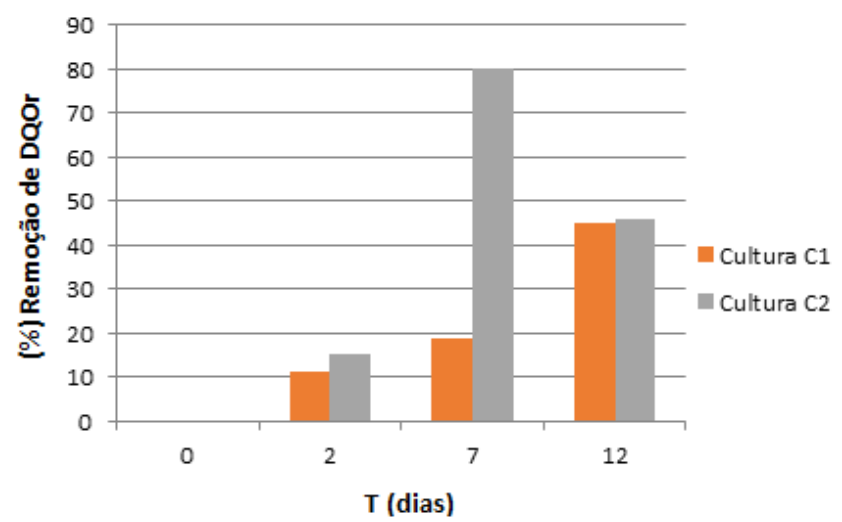

Ao analisar a Figura 4, pode-se verificar que a cultura C2 apresentou maior potencial na biodegradação do biodiesel. A maior remoção foi observada em 7 dias de processo chegando a $80 \%$ de remoção. No $12^{\circ}$ dia verifica-se que para essa cultura $(\mathrm{C} 2)$ foi observada uma queda na remoção. Isto sugere que essa diminuição pode ter sido decorrente de alterações no meio que promoveram a produção de componentes metabólicos que ocasionaram aumento da DQO, portanto menor remoção da mesma.

Estes resultados sugerem que a cultura que apresentou maior potencial em biodegradar biodiesel foi a cultura $\mathrm{C} 2$ no tempo de processo de 7 dias.

\section{CONCLUSÕES}

A cultura que apresentou maior potencialidade na biodegradação do biodiesel foi a cultura C2 oriunda de processo anaeróbio no tempo de 7 dias de processo. 


\section{REFERÊNCIAS}

ANDRADE, J. A., AUGUSTO, F.; JARDIM, I. C. S. F. Biorremediação de solos contaminados por petróleo e seus derivados. Eclética Química v. 35, n. 3, p. 17-43, 2010.

APHA. Standard Methods for the Examination of Water and Wastewater. 20th ed. APHA: Washington, 1998.

Norma Técnica Interna SABESP. NTS 013. Sólidos - Método de Ensaio. São Paulo. 8 p. 1999.

BIELICKA, K.; KACZOREK, E.; OLSZANOWSKI, A.; VOELKEL, A. Examination of biodegradation of hydrocarbons in emulsified systems, Poblish J. Environ. Stud. v.11 pp. 11-16, 2002.

GOGOI, B.K.; DUTTA, N.N.; GOSWAMI, P.; KRISHNA MOHAN, T.R. A case study of bioremediation of petroleum-hydrocarbon contaminated soil at a crude oil spill site, $A d v$. Environ. Res. v. 7. pp. 767-782, 2003.

LAKHA, S.S.; MILLER, M.; CAMPBELL, R.G.; ELAHIMANESH, K.S.P.; HART, M.M.; TREVORS, J.T. Microbial gene expression in soil: methods, applications and challenges, J. Microbiol. Meth. pp. 9-19, 2005.

PIEDADE DÍAZ, M.; GRIGSON, S. J.W.; PEPPIATT, C. J.; BURGESS1, J. G. Isolation and Characterization of Novel Hydrocarbon-Degrading Euryhaline Consortia from Crude Oil and Mangrove Sediments. Mar. Biotechnol. v.2, pp. 522-532, 2000.

TOWNSEND, G.T.; PRINCE, R.C.; SUFLITA, J.M. Anaerobic biodegradation of alicyclic constituents of gasoline and natural gas condensate by bacteria from an anoxic aquifer, FEMS Microbiol. Ecol. v. 49, p. 129-135, 2004.

VIEIRA, P.A.; VIEIRA, R.B.; RIBEIRO E.J.; CARDOSO V.L. The sedimentation of mixed cultures used in the treatment of effluents generated from terrestrial fuel distribution terminals, J. Hazard. Mater., 184(1-3), 177-183, 2010.

VIEIRA, P.A.; VIEIRA, R.B.; DE FRANÇA, F.P.; CARDOSO, V.L. Biodegradation of effluent contaminated with diesel fuel and gasoline. Journ. Hazard. Mat., 140(1-2), 5259, 2007.

\section{AGRADECIMENTOS}

Os autores agradecem ao apoio financeiro da Fundação de Amparo à Pesquisa do Estado de Minas Gerais - FAPEMIG, CAPES e CNPq - Brasil e à Faculdade de Engenharia Química (FEQUI-UFU) e as Empresas Caramuru Alimentos S/A - São Simão - GO pelas amostras de biodiesel e a Souza Cruz- Fábrica Uberlândia pela amostra de lodo anaeróbio. 